\title{
Gerenciamento de embalagens de lubrificantes pós-consumo - Uma análise crítica
}

\author{
Management of lube oil container $-\mathrm{A}$ review \\ Harley M. Martins ${ }^{1}$, Alexandre Lioi Nascentes ${ }^{2}$, Maria José de O. C. Guimarães ${ }^{3}$, Juacyara Carbonelli \\ Campos.
}

Como citar esse artigo. Martins HM, Nascentes AL, Guimarães MJOC, Campos JC. Gerenciamento de embalagens de lubrificantes pós-consumo - Uma análise crítica. Revista Teccen. 2015 Jan./Jun.; $08 \quad(1): \quad 13-19$

\begin{abstract}
Resumo
Este trabalho apresenta uma avaliação das sistemáticas atualmente praticadas no município do Rio de Janeiro para tratamento e disposição de embalagens pós-consumo de lubrificantes automotivos. O diagnóstico foi realizado através de pesquisa de campo com entrevista estruturada e visita às instalações de pontos de geração, centrais de triagem e recicladoras desse tipo de resíduo. Os resultados obtidos tornam evidente que os programas de logística reversa implantados no município em estudo apresentam deficiências significativas no que tange, principalmente, às sistemáticas para separação da fração oleosa do resíduo plástico e armazenamento temporário, com consequências diretas associadas ao transporte seguro e a viabilidade do processo de reciclagem. Os dados demonstram lapso entre as práticas vigentes e os preceitos preconizados pela Política Nacional de Resíduos Sólidos, especificamente no que tange ao inciso IV, artigo 33, Lei 12.305/10. Palavras-Chave: Lubrificantes. Logística Reversa. Lei 12.305/10. Embalagens PEAD. Pós-consumo.
\end{abstract}

\begin{abstract}
This paper presents an evaluation of current practices in Rio de Janeiro City for treatment and disposal of postconsumer packaging automotive lubricants. The diagnosis was made by using a structured field survey, including the oil change points, screening location and recycling company. The results reveal that the reverse logistics programs implemented in the locality under study have significant weaknesses in relation to the systematic separation of the oily waste in plastic bottles and temporary storage with direct consequences associated with the safe transport and viability of the recycling process. The data show gap between current practices and precepts advocated by the National Solid Waste Polic, specifically with respect to item IV, Article 33, Law 12.305/10.

Keywords: Lubricants. Reverse Logistics. Law 12.305/10. HDPE containers. Post-consumer.
\end{abstract}

\section{Introdução}

A destinação final das embalagens plásticas após consumo do produto acondicionado representa um significativo problema ambiental. Os materiais plásticos têm, geralmente, ciclos de vida $\operatorname{curtos}^{1} \mathrm{e}$, quando rejeitados, se degradam muito lentamente, se acumulando no meio ambiente, contribuindo com o agravamento de vários problemas como impermeabilização dos solos, aumento do volume de lixões com proliferação de doenças, assoreamento dos rios e lagos, dentre outros ${ }^{2,3}$.

No caso dos frascos de óleos lubrificantes automotivos, há fator crítico adicional associado à permanência de fração oleosa residual pósabastecimento: ${ }^{4}$ informam que - em média - $20 \mathrm{~g}$ de óleo permanecem nas embalagens de $1 \mathrm{~L}$.

Segundo ${ }^{5}$, com confirmação do Ministério do Meio Ambiente ${ }^{6}$, a presença de óleo lubrificante remanescente impõe periculosidade ainda maior ao resíduo em questão, quando considerado o potencial de contaminação do meio por esse hidrocarboneto e seus aditivos, através de diversas vias (solo, meio aquoso e atmosférico - queima). Lubrificantes são formulados a partir de óleos básicos e aditivos. Aditivos podem conter fenol, compostos de zinco, enxofre e seus compostos, compostos de cálcio e magnésio, entre outros. Essas substâncias têm enorme poder de contaminação ${ }^{7}$. De acordo com a classificação proposta pela norma NBR 10.004/04 $\mathrm{da}^{8}$, os frascos de óleo lubrificante pós-consumo, contendo óleo remanescente do abastecimento são enquadrados na classe I - Perigosos.

No contexto apresentado acima, os processos de reciclagem se inserem como alternativa ambientalmente adequada. Dentre as metodologias conhecidas para reciclagem de plásticos,noBrasil, emespecial porquestões de custos, foi a reciclagem mecânica, ou secundária, que

1. Departamento de Gestão Ambiental, Instituto Federal do Rio de Janeiro - IFRJ - Rio de Janeiro-RJ, Brasil.

2. Departamento de Engenharia, Universidade Federal Rural do Rio de Janeiro - UFRRJ - Instituto de Tecnologia, Seropédica-RJ, Brasil.

3. Escola de Qímica, Universidade Federal do Rio de Janeiro - UFRJ - Centro de Tecnologia, Rio de Janeiro-RJ, Brasil.

4. Escola de Qímica, Universidade Federal do Rio de Janeiro - UFRJ - Centro de Tecnologia, Rio de Janeiro-RJ, Brasil. 
se consolidou. Nesse tipo de reciclagem, a embalagem é fragmentada e passa por processo de extrusão para geração do novo artefato. Para tal é fundamental que o material plástico esteja isento de contaminantes.

A inexistência de um processo eficaz para descontaminação das embalagens de lubrificantes tem tornado inviável processos convencionais de reciclagem. De forma global, conforme ${ }^{9}$, tradicionalmente, plásticos contaminados com resíduo oleoso apresentam grande dificuldade para reciclagem, em especial por conta de necessárias etapas de descontaminação. $\mathrm{Na}$ verdade, a limpeza ambiental e economicamente viável desse tipo de resíduo é um problema antigo, que permanece extremamente atual e tem âmbito global.

${ }^{10}$ Discutiram problemas de lavagens que consideram solventes combustíveis, inflamáveis e halogenados, além de reforçar o inconveniente da geração e necessidade de tratamento dos efluentes gerados. Nesse mesmo trabalho, esses pesquisadores propõem método para solubilização e remoção do óleo residual com dióxido de carbono pressurizado em estado líquido ou supercrítico. ${ }^{7}$ Depositaram patente nos Estados Unidos estabelecendo método para lavagem com solvente e secagem com nitrogênio, associado à fragmentação do frasco. ${ }^{11}$ Apresentou um complexo sistema de limpeza dos frascos de lubrificantes pósconsumo com soluções aquosas de ácido sulfônico e/ou detergentes, com turbulência e ausência de ar, associado à drenagem térmica e retirada mecânica dos rótulos: alta rotação e impactos de cavitação, geradas pela rápida evaporação/condensação, fornecem energia suficiente para liberar moléculas de óleo fortemente ligadas ${ }^{11}$. Outros autores, como é o caso de ${ }^{12}$ que depositaram patentes relacionadas com a limpeza de embalagens em geral e indicam utilização de solventes, sem mencionar métodos de eliminação ou reciclo.

Diversas técnicas foram estudadas (incluindo solventes aquosos e não aquosos, fluidos em estado supercrítico, etc., entretanto todas são consideradas caras e geradoras de resíduos adicionais como subprodutos ${ }^{9}$.

Ainda assim, reportagens e artigos recentes ${ }^{13,9}$ dão conta de metodologias que teriam sido desenvolvidas para reciclagem direta das embalagens de lubrificantes (com resíduo oleoso), inclusive a partir de blendas e compósitos com fibras. Entretanto, essas metodologias se restringem aos processos de extrusão e injeção e, em todos os casos, o material reciclado é destinado a fins muito específicos e pouco nobres (baixo valor agregado).

Com relação à logística reversa de plásticos ${ }^{14}$ analisam o andamento desse processo no Brasil, citando oportunidades e desafios. Entretanto, esse trabalho se limita ao cenário do PET e, apesar de publicado em 2011, não aborda nem menciona requisitos da Lei 12.305/10 ou do Decreto 7.404/10 (principais instrumentos reguladores da questão no país) ${ }^{15}$.
No caso específico dos frascos de lubrificantes pós-consumo, empresa americana implantou, em 1999, programa no Estado da Califórnia que consistiu na coleta e transporte de embalagens usadas de óleo para centros de triagem. A metodologia utilizada não é divulgada ${ }^{16}$ e não há informações atuais sobre continuidade do processo.

No Brasil, a Lei Federal 12.305/10 instituiu a nova Política Nacional de Resíduos Sólidos ${ }^{15}$ e, em seu artigo 33 inciso IV, obriga a implantação de logística reversa - com coleta e destinação adequada - para óleos lubrificantes, seus resíduos e embalagens. Essa lei atribui tal responsabilidade a todos os atores envolvidos na cadeia produtiva respectiva.

No Estado do Rio de Janeiro foi aprovada, em 2000, uma Lei Estadual $\left(\mathrm{n}^{\mathrm{o}}\right.$. 3.369) ${ }^{17}$ que tem relação com o gerenciamento ambientalmente adequado desse tipo de resíduo, tendo em vista que impõe obrigações a "todas as empresas que utilizam garrafas e embalagens plásticas na comercialização de seus produtos".

Em dezembro de 2012, por força do disposto na Lei 12.305/10 supra ${ }^{15}$, foi firmado no Estado do Rio de Janeiro o primeiro acordo setorial atendendo aos princípios da Política Nacional de Resíduos Sólidos, prevendo a implantação da logística reversa pelas empresas envolvidas na fabricação, importação, distribuição e comercialização de óleos lubrificantes embalados.

Oreferido acordo setorial foi baseado no programa intitulado "Jogue Limpo", associado a sindicatos das empresas produtoras. Os documentos oficiais do programa sugerem presença efetiva em seis Estados da federação $0^{18}$, inclusive no Estado do Rio de Janeiro.

Diante disso, o presente trabalho tem como objetivo realizar levantamento e análise crítica da metodologia utilizada nos postos de combustíveis do município do Rio de Janeiro para tratamento e disposição dos frascos plásticos de lubrificantes automotivos pósconsumo, especialmente no que tange ao escoamento do resíduo oleoso, armazenamento temporário e práticas de coleta e transporte à reciclagem.

\section{Materiais e Métodos}

\section{Pesquisa de campo - Avaliação do cenário atual}

Foram visitados 56 postos combustíveis que comercializam lubrificantes automotivos no município do Rio de Janeiro - Figura 1. A amostragem realizada representa $7,3 \%$ dos revendedores autorizados e em operação na cidade ${ }^{19} \mathrm{e}$ foi conduzida de forma a obter dados de cada uma das cinco áreas de planejamento oficiais, representativas da municipalidade ${ }^{20}$.

De forma a assegurar representatividade da pesquisa em relação às diferentes marcas produtoras 


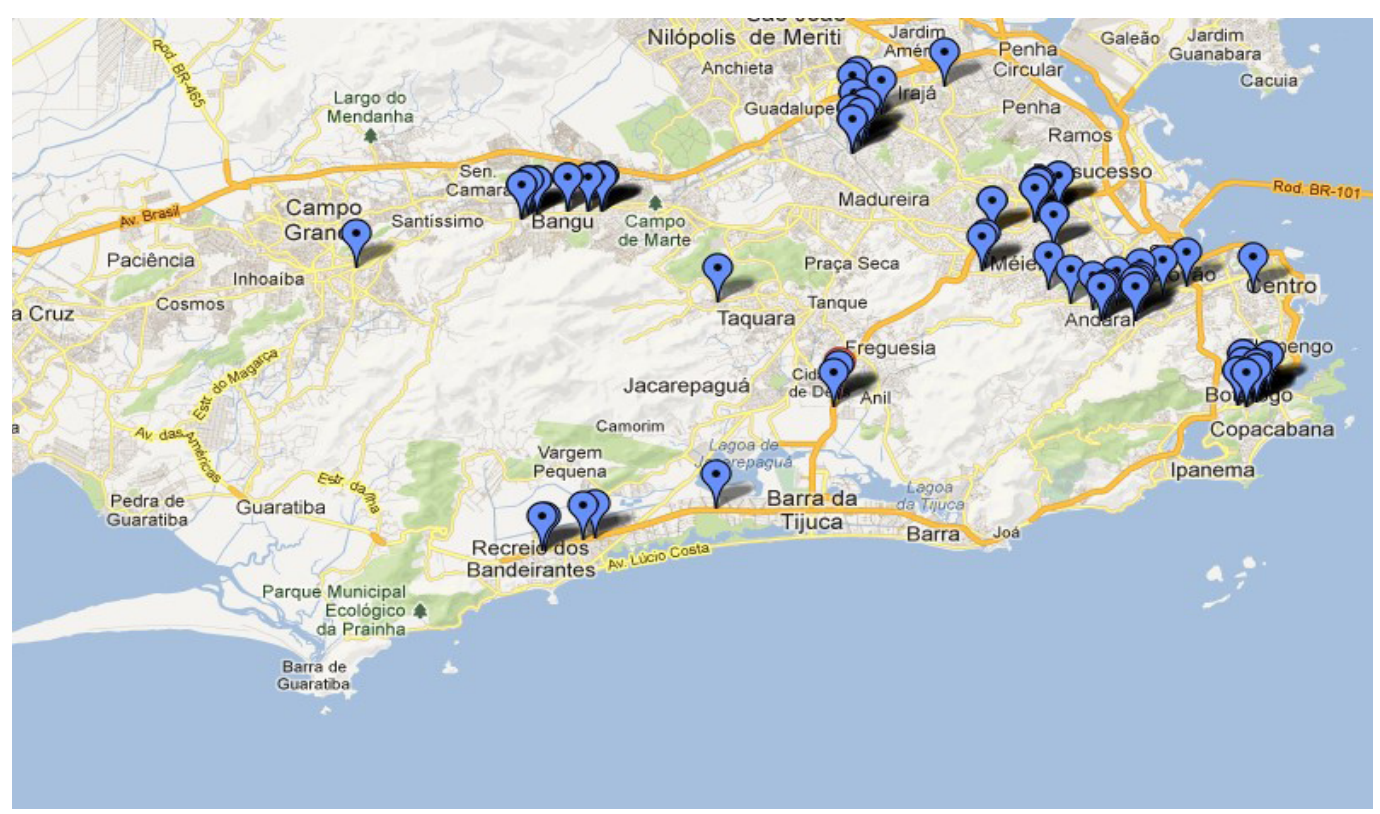

Figura 1. Distribuição geográfica dos revendedores de lubrificantes avaliados. Fonte: Google Maps

e aos diferentes lubrificantes disponíveis no mercado, foram visitados revendedores de variadas "bandeiras", entre as quais, Petrobras Distribuidora - BR, Shell, Forza, Ale, Cosan e Ipiranga; além de postos "Bandeira Branca" (revendedores de combustíveis não ligados exclusivamente a nenhum dos produtores ou grandes distribuidores).

Durante o levantamento de campo foi observada e registrada a metodologia vigente para escoamento do óleo residual, a estrutura e utilização do aparato coletor, as sistemáticas de manuseio e armazenamento temporário, entre outras.

Como recurso metodológico para coleta e consolidação das informações, utilizou-se da ferramenta Entrevista Estruturada ${ }^{21}$, que se baseou em questionário padrão, desenvolvido em função de questões críticas prédefinidas (Figura 2).

As pesquisas de campo incluíram, também, outros atores envolvidos na logística reversa dos frascos de lubrificantes automotivos. Foram avaliados veículos utilizados no recolhimento e visitadas uma central de triagem e uma recicladora (todos envolvidos no programa "Jogue Limpo") como meio de identificar, com mais detalhes, as características operacionais e as dificuldades do sistema vigente.

\section{PESQUISA DE CAMPO}

1) IDENTIFICAC̣ÃO DO PONTO GERADOR

Data:

1.1 Posto Visitado:

1.2 Bandeira:

1.3 Endereço:

1.4 Funcionário Entrevistado (opcional):

\section{2) METODOLOGIA UTILIZADA}

\begin{tabular}{|c|c|c|}
\hline \multicolumn{3}{|l|}{ 2.1 Aparato Coletor de Óleo: } \\
\hline 2.1.1 Existe? & $(\mathrm{S})$ & $(\mathrm{N})$ \\
\hline 2.1.2É utilizado para escorrimento das embalagens de lubrificantes? & (S) & $(\mathrm{N})$ \\
\hline 1.3 Os frascos são mantidos em posição adequada ao escoamento? & (S) & $(\mathrm{N})$ \\
\hline 1.4 É utilizado para colocação de outros materiais? & (S) & $(\mathrm{N})$ \\
\hline 1.5 A estrutura é adequad & (S) & (N) \\
\hline frasco? & (S) & $(\mathrm{N})$ \\
\hline 7 Há definição de tempo mínimo de escorrimento? & (S) & $(\mathrm{N})$ \\
\hline \multicolumn{3}{|l|}{ 2.2 Destinação das Embalagens: } \\
\hline 2.2.1 Há P & $(\mathrm{S})$ & $(\mathrm{N})$ \\
\hline Caso afirmativo, há documento comprobatório da destinação? & (S) & $(\mathrm{N})$ \\
\hline Caso afirmativo, qual a periodicidade da coleta? & & \\
\hline \multicolumn{3}{|l|}{$\begin{array}{l}\text { 2.2.2 Onde as embalagens são armazenadas? } \\
\text { ( ) Não são armazenadas ( ) Em sacos de lixo ( ) Em Tambores ( ) }\end{array}$} \\
\hline 2.3 As embalagens são armazenadas tampadas? & $(\mathrm{S})$ & $\overline{(N)}$ \\
\hline 2.4 Há compactação ou fragmentação das embalagens para armazena & & \\
\hline 2.5 Há compactação ou fragmentaç & (S) & (N) \\
\hline 2.6 Há escorrimento de óleo para o solo durante o armazenamento? & (S) & (N) \\
\hline
\end{tabular}

Figura 2. Formulário utilizado para entrevista estruturada. 


\section{Resultados e Discussão}

\section{Avaliação do cenário atual - Pontos de geração}

As avaliações realizadas nos postos de serviços revendedores de lubrificantes automotivos foram suficientes para revelar a falta de estrutura e ineficácia das atuais metodologias utilizadas para tratamento e destinação dos resíduos pós-consumo dessa cadeia produtiva.

As entrevistas estruturadas foram capazes de fornecer dados objetivos representantes das práticas vigentes, que foram organizados e são analisados a partir das tabelas que se seguem. Além disso, durante a pesquisa de campo, evidências da rotina estabelecida foram capturadas em registros fotográficos que também são apresentados em sequência.

ATabela 1 reúne e trabalha os principais resultados relacionados ao processo separação do resíduo oleoso.

Tabela 1. Resultados da pesquisa de campo - Separação do resíduo oleoso.

\begin{tabular}{|c|c|}
\hline $\begin{array}{l}\text { Parâmetro Analisado no Revendedor } \\
\text { Processo de Separação }\end{array}$ & $\begin{array}{l}\text { Resultado } \\
\text { (\%) }\end{array}$ \\
\hline Possuem aparato coletor de óleo & 91,1 \\
\hline $\begin{array}{l}\text { Utilizam o aparato para escoamento } \\
\text { gravitacional do resíduo de abastecimento }\end{array}$ & 35,7 \\
\hline $\begin{array}{l}\text { Há alguma padronização quanto ao } \\
\text { tempo mínimo de escoamento }\end{array}$ & 3,6 \\
\hline $\begin{array}{l}\text { Há alguma padronização quanto } \\
\text { ao posicionamento do frasco para } \\
\text { escoamento }\end{array}$ & 3,6 \\
\hline $\begin{array}{l}\text { Estrutura do aparato coletor permite } \\
\text { escoamento eficaz do resíduo oleoso }\end{array}$ & 0,0 \\
\hline $\begin{array}{l}\text { Utilizam aparato como depósito de outros } \\
\text { materiais }\end{array}$ & 62,5 \\
\hline $\begin{array}{l}\text { Há tentativa de posicionamento das } \\
\text { embalagens de modo a permitir algum } \\
\text { escoamento do óleo residual }\end{array}$ & 16,1 \\
\hline
\end{tabular}

Fonte. Arquivo pessoal.

Depreende-se dos resultados tabuados que $91,1 \%$ dos postos entrevistados possuem um aparato coletor de óleo, comumente chamadode "pingadeira", mas somente em $35,7 \%$ desses revendedores esse equipamento é utilizado para escorrimento do resíduo oleoso. Mesmo onde foi observada a utilização do equipamento, a separação da fração oleosa é praticamente nula em mais da metade dos casos: em apenas $16,1 \%$ das unidades entrevistadas foram encontrados frascos pósconsumo em posições que permitiam, minimamente, $o$ escoamento gravitacional.
Ressalta-se que o aparato coletor de óleo supracitado é uma espécie de funil metálico com pouca, ou nenhuma inclinação com a horizontal. Esse equipamento teria como finalidade permitir o escoamento gravitacional do óleo residual, entretanto, pode-se afirmar que a estrutura da peça não é adequada ao seu objetivo, em especial pela inexistência de suportes adaptáveis aos contêineres e pela pequena angulação da bandeja metálica.

Ademais, somado à inadequação da estrutura de todos os modelos de "pingadeiras" encontrados, o estudo demonstra que em $62,5 \%$ dos casos os aparatos são utilizados para disposição de outros materiais (filtros, estopas, panos, etc.) e, ainda, que apenas $3,6 \%$ dos postos de serviço declaravam possuir algum tipo de padronização, seja relacionada com a posição da embalagem seja relacionada com o tempo de escorrimento. A Figura 3 contém registros fotográficos que evidenciam algumas das constatações de nãoconformidades do processo de separação e ilustram os resultados acima citados.
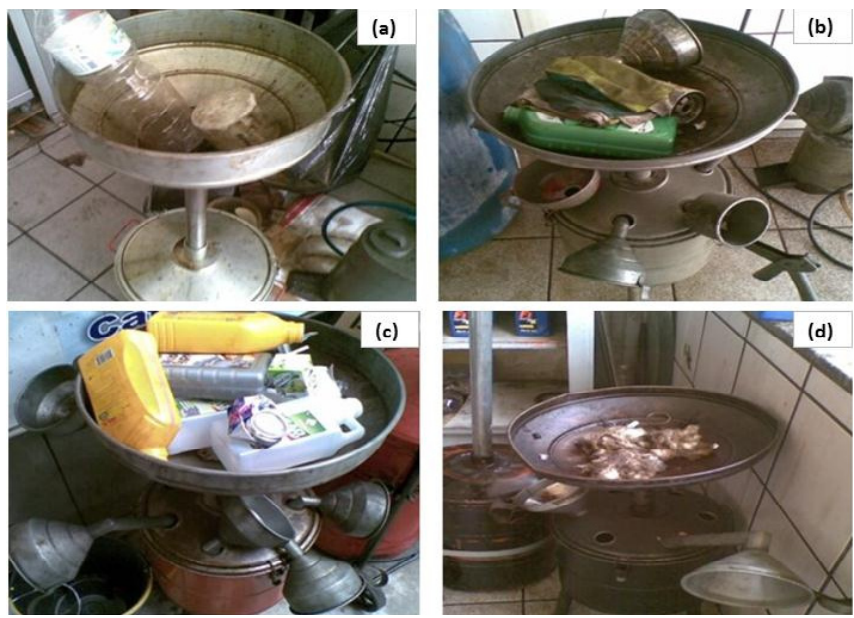

Figura 3. (a), (b), (c), (d) - Inadequações do processo de separação da fração oleosa.

Fonte: Arquivo pessoal

Como resultado da avaliação das sistemáticas de armazenamento temporário e disposição das embalagens plásticas pós-consumo, que representou a segunda etapa da entrevista estruturada realizada, foi elaborada a Tabela 2. Nessa Tabela são considerados resultados da investigação sobre a participação dos pontos geradores em programas de coleta com destinação à reciclagem e reportados dados relacionados com a metodologia utilizada para armazenamento temporário dos frascos.

As entrevistas revelaram que $96,4 \%$ dos postos dizem armazenar os frascos de lubrificantes pós venda e que $92,9 \%$ afirmaram participar de programa de coleta dessas embalagens para envio à reciclagem, porém apenas $48,2 \%$ possuíam documento comprobatório de destinação ao programa de logística reversa mencionado. 
Tabela 2. Resultados relacionados à participação em programas de logística reversa e às características do armazenamento temporário realizado.

\begin{tabular}{|cc}
\hline $\begin{array}{c}\text { Parâmetro Analisado no Revendedor } \\
\text { Armazenamento e destino }\end{array}$ & $\begin{array}{c}\text { Resultado } \\
\text { (\%) }\end{array}$ \\
\hline $\begin{array}{c}\text { Declaram participar de programa de } \\
\text { coleta seletiva }\end{array}$ & 92,9 \\
$\begin{array}{c}\text { Possuem documento comprobatório da } \\
\text { participação em programa de coleta } \\
\quad \text { Embalagens são armazenadas }\end{array}$ & 48,2 \\
destampadas (como padrão recorrente) & 75,0 \\
Foi evidenciado escorrimento de óleo \\
diretamente para solo desprotegido \\
$\begin{array}{c}\text { Embalagens são compactadas e/ou } \\
\text { fragmentadas para facilitar separação e } \\
\text { transporte }\end{array}$ \\
$\begin{array}{c}\text { Não há armazenagem. Embalagens pós- } \\
\text { consumo são destinadas ao lixo comum }\end{array}$ \\
\hline
\end{tabular}

Fonte. Arquivo pessoal.

Em relação à forma de armazenamento temporário, observou-se que os contêineres são estocados destampados, como padrão recorrente, em $75 \%$ dos casos, representando risco de contaminação na armazenagem e durante o transporte (situação ilustrada pela Figura 4).
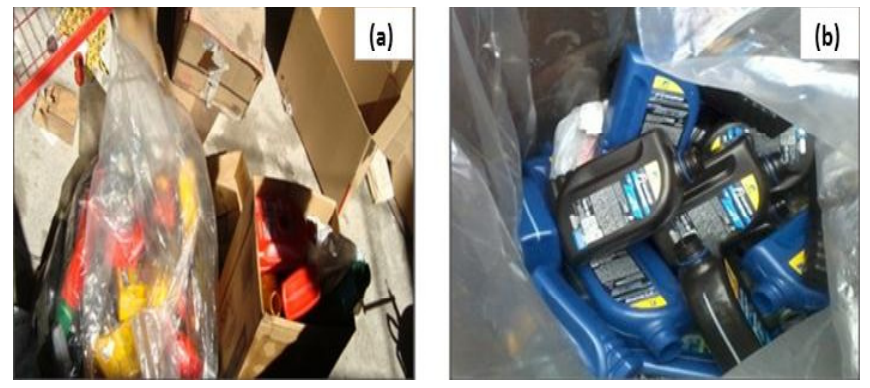

Figura 4. (a), (b) - Armazenamento dos frascos de lubrificantes pós-consumo. Fonte: Arquivo pessoal

Além disso, em 12,5\% dos locais pesquisados foram encontradas evidências de escorrimento de óleo diretamente para o solo desprotegido ou para galerias pluviais não interligadas com redes de coleta. Outra característica marcante do armazenamento realizado é a prática de estocagem dos frascos juntamente com outros materiais. A Figura 5 apresenta evidências de algumas das diversas situações constatadas.

A Figura 6 apresenta gráfico que retrata em que estrutura/material ficam reunidas as embalagens pósuso aguardando coleta. Observa-se que a estocagem é majoritariamente realizada em sacos de lixo, no entanto foram encontradas outras formas de armazenamento, como puderam demonstrar os registros fotográficos já apresentados nas Figuras 4 e 5.

Ademais, deve-se destacar que 3,6\% dos revendedores, autorizados pela Agência Nacional do Petróleo, Gás Natural e Biocombustíveis (ANP) e constituintes do universo amostral da pesquisa, declaram destinar esse resíduo perigoso para o lixo comum.
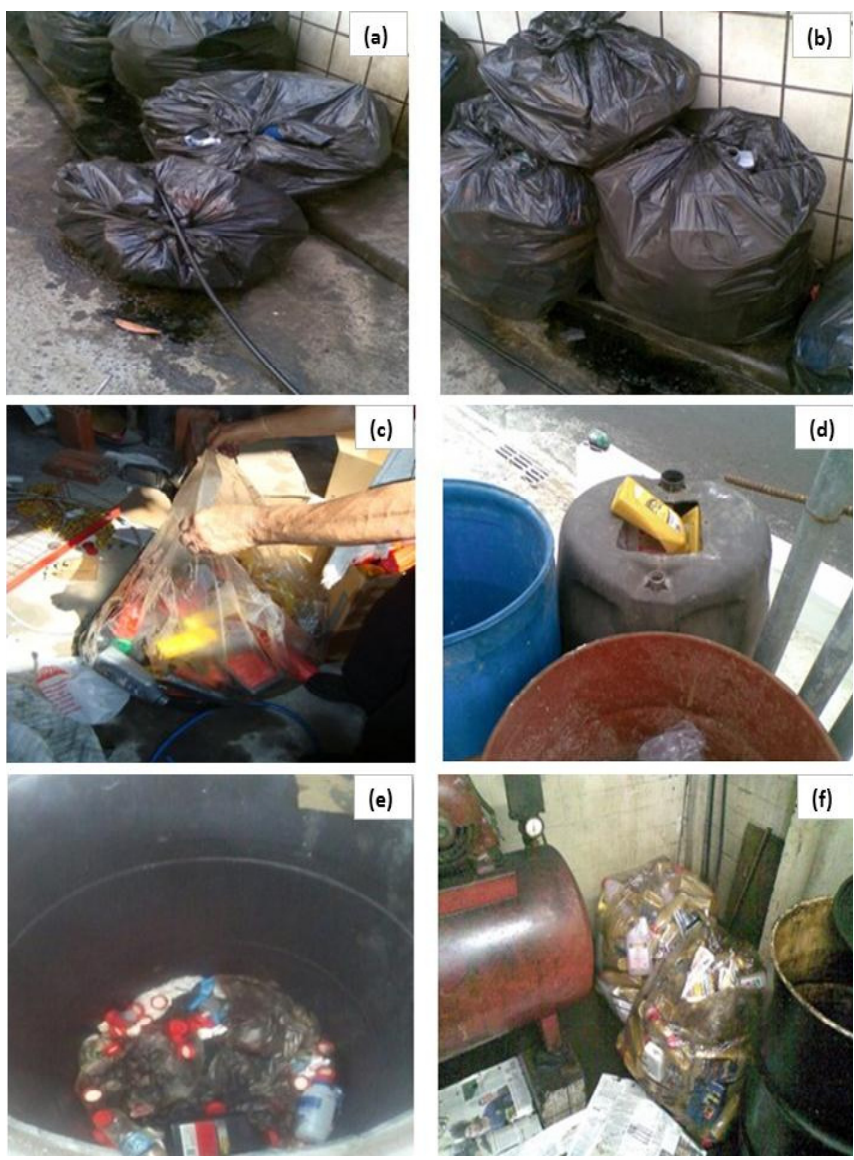

Figura 5. (a), (b), (c), (d), (e), (f) - Armazenamento das embalagens pós-consumo - Evidências de situações inadequadas. Fonte: Arquivo pessoal
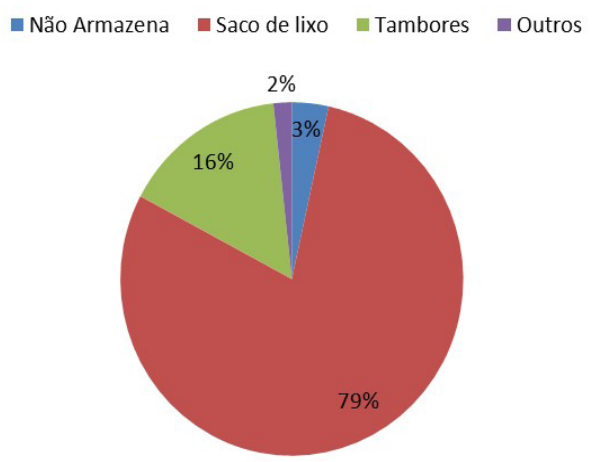

Figura 6. Estrutura/Material utilizado para armazenamento temporário das embalagens.

Fonte: Arquivo pessoal

\section{Avaliação do Cenário Atual: Central de Triagem}

A avaliação conduzida na Central de Triagem do programa "Jogue Limpo", localizada no bairro Jardim Primavera em Duque de Caxias/RJ foi suficiente para 
verificação do fluxo da operação e análise crítica da sistemática praticada.

Uma das importantes constatações dessaetapa dapesquisa de campo relaciona-se com o claro entrave logístico associado ao transporte das embalagens plásticas pós-consumo em sua conformação original, ou seja, não fragmentadas ou compactadas nos pontos de geração: os veículos saem da central com uma rota definida e precisam interromper a coleta e retornar ao galpão toda vezque o volume do baú é preenchido, mesmo considerando que o caminhão suportaria carga mássica muito maior.

Além disso, os produtos de recolhimento encontrados na central de triagem (Figura 7) tornam evidente que as embalagens, em sua grande maioria, são armazenadas e transportadas destampadas, inserindo ao processo significativo risco de contaminação ambiental por derramamento de óleo ao longo do percurso.

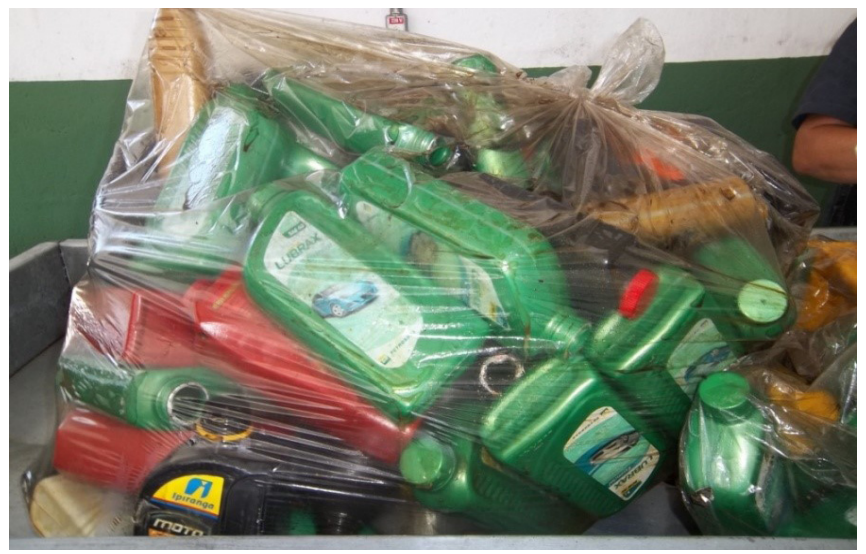

Figura 7. Embalagens coletadas pela central de triagem - Plástico filme com óleo e diversas embalagens destampadas. Fonte: Arquivo pessoal

Outra evidência representativa da inadequação do processo de logística reversa implantado pôde ser obtida, nessa etapa, quando observado recipiente contendo significativa quantidade de óleo livre (resíduo oleoso) proveniente das embalagens recolhidas pela operadora (Figura 8), que comprova resultado da ineficaz separação da fração oleosa pelos pontos de troca de óleo.

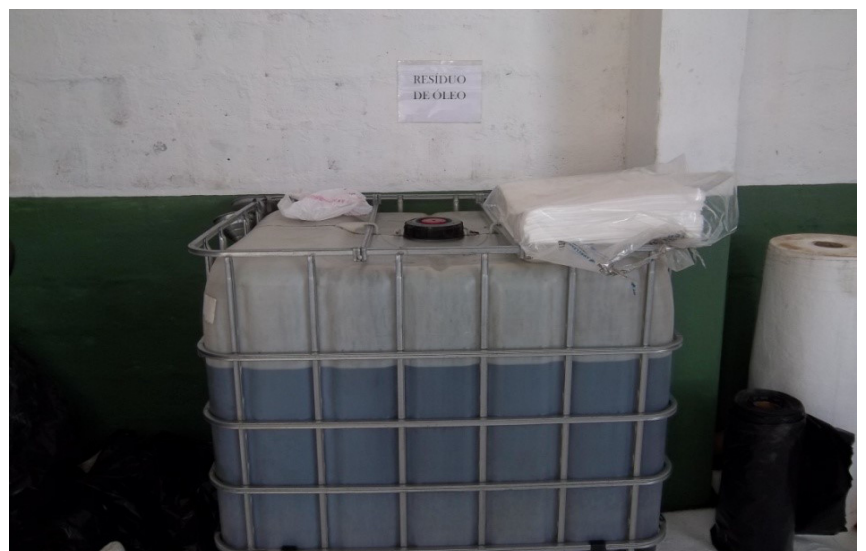

Figura 8. Container com resíduo oleoso que chega até a central de triagem. Fonte: Arquivo pessoal

\section{Avaliação do cenário atual - Recicladora}

Foram visitados os dois galpões da recicladora utilizada pelo único programa de logística reversa implantado no país. A empresa visitada opera de forma similar as demais recicladoras de plástico instaladas no Brasil, realizando reciclagem mecânica primária (rejeitos industriais) e secundária (resíduos pós-consumo). São desenvolvidos processos de aglutinação, extrusão, granulação, injeção, dentre outros.

No caso específico dos frascos de lubrificantes, a recicladora optou por realizar reciclagem direta dos resíduos recebidos e não efetua lavagem do material. Foi evidenciado que o teor de óleo residual nas embalagens tem total impacto nas operações da recicladora. Pode-se perceber, por exemplo, que a resina reciclada - em diversos estágios do processo - apresenta óleo em sua superfície e que o artefato extrusado ou injetado mantém odor de óleo queimado.

Com base nessa situação, são fabricados pela empresa somente artefatos de baixo valor agregado, em que o comprador não tem grandes restrições relacionadas à qualidade intrínseca do material.

Além disso, cabe ressaltar que a existência de óleo residual nas embalagens impede que a empresa utilize o processo de sopro e, mais ainda, que o excesso de óleo, em muitos casos, causa deformação nas peças injetadas.

\section{Considerações finais}

As avaliações realizadas nos postos de serviços revendedores de lubrificantes automotivos e demais atores envolvidos no processo de recolhimento e destinação das embalagens pós-uso desse produto, atuantes no município do Rio de Janeiro, foram suficientes para revelar a falta de estrutura e ineficácia dos atuais procedimentos utilizados para gerenciamento dos resíduos pós-consumo dessa cadeia produtiva.

Os resultados da pesquisa tornam evidente que os programas de logística reversa implantados no município em estudo apresentam deficiências significativas no que tange, principalmente, às sistemáticas para separação da fração oleosa do resíduo plástico e armazenamento temporário, com consequências diretas associadas ao transporte seguro e a viabilidade do processo de reciclagem.

No que se relaciona, especificamente, com as práticas de remoção da fração oleosa residual, ressaltase que os aparatos coletores de óleo, utilizados para o escorrimento gravitacional do óleo remanescente, apresentam estruturas que dificultam o escoamento, além de serem utilizados de forma inadequada, sem qualquer metodologia estabelecida e implementada com 
orientações para posicionamento adequado do frasco, tempo mínimo de escoamento, etc.

Ademais, as práticas atuais de armazenamento temporário e transporte das embalagens pós-uso também carecem de padronizações que garantam a segurança ambiental dessas operações, com minimização dos riscos potenciais de contaminação do solo e águas subterrâneas.

Por fim, como resultado geral, deve-se grifar que as avaliações de campo demonstraram que o Programa "Jogue Limpo", base do acordo setorial firmado pelo Ministério do Meio Ambiente para logística reversa de embalagens de lubrificantes, deve ser considerado como iniciativa importante do setor produtivo, mas apresenta práticas que não estão conformes com Normas Técnicas aplicáveis nem com requisitos compulsórios previstos pela Legislação ambiental brasileira. Como mostrado, o programa é alicerçado em técnicas ineficazes para remoção da fração oleosa, métodos de armazenamento pouco seguros e em operações de transporte e reciclagem com viabilidade econômica ambiental questionável.

\section{Referências}

1 Panda, A.K; Singh, R.K; Mishra, D.K. (2009). Thermolysis of waste plastics to liquid fuel. Renewable and Sustainable Energy Reviews.

2 Braga, B. et al.(2005). Introdução à engenharia ambiental. 2ed. São Paulo: Prentice Hall.

3 Tenório, J.A.S; Espinosa, D.C.R. (2004). Controle Ambiental de Resíduos. In: Junior, P.A; Roméro, M.A; Bruna, G.C. editores. Curso de Gestão Ambiental. 1ed. Barueri, SP. Manole, p.155-211.

4 Lei, Y.; Wu, Q. (2009). Composites made of Thermoplastic Polymers, residual oil, and Cellulosic Fibers. WO 2009/079273 A2. Patent Cooperation Treaty.

5 Xavier, L.H.; Cardoso, R.; Matos, R.M.; Adissi, P.J. (2006). Legislação ambiental sobre destinação de resíduos sólidos: o caso das embalagens plásticas pós-consumo. XII SIMPEP.

6 MMA. (2011). Plano Nacional de Resíduos Sólidos - Versão Preliminar. Ministério do Meio Ambiente/Governo Federal.

$7 \quad$ Kim et al. (2001) Process for cleaning Plastics for recycling them. United States Patent.

8 Associação Brasileira de Normas Técnicas - ABNT (2004). NBR 10.004. Resíduos Sólidos. Classificação.

9 Lei, Y.; Wu, Q. (2011). Recycling Engine Oil Containers to Prepare Wood-Plastic Composite. Wiley Online Library.

10 Smith, et al. (1998). Method to separate and recover oil and plastic from plastic contaminated with oil. International Publication Number US $5,711,820$. United States Patent.

11 ZAPP, Jorge. (2011). System for Recycling of HDPE from motor-oil containers. United States Patent.

12 Musha, T. Yamamoto, S., Takeda, T. (2003). Cleaning Method of Containers and Apparatus Thereof. United States Patent.

Brasil. Lei 12.305/10. Institui a Política Nacional de Resíduos Sólidos, altera a Lei Federal 9.605, de 12 de fevereiro de 1998 e dá outras Providências.

13 Kudrjawzew. V. (2009). Operação piloto. Revista Plástico Moderno. Edição nº413 - Março de 2009.
14 Coelho, T.M., R. Castro1, J.A. Gobbo Jr. (2011) PET containers in Brazil: opportunities and challenges of a logistics model for post-consumer waste recycling. Resources, Conservation and Recycling 55, 291-299.

15 Brasil. Decreto 7.404/10. Regulamenta a Lei no 12.305, cria o Comitê interministerial da Política Nacional de Resíduos Sólidos e o Comitê Orientador para a Implantação dos Sistemas de Logística Reversa, e dá outras providências.

16 Fix-Corp International, Inc. (1999). Process Recycles Plastic MotorOil Containers Without Chemical Additives.

17 Rio de Janeiro. (2000). Lei Estadual RJ 3.369/00 - Estabelece Normas para a Destinação Final de Garrafas Plásticas e dá outras providências.

19 Jogue Limpo (2013). O Programa. Disponível em: <http://www. programajoguelimpo.com.br/index.php/oprograma $>$ Acesso:10 jun. 13.

19 Agência Nacional do Petróleo, Gás Natural e Biocombustíveis ANP (2013). Revenda de Combustível Automotivo - Consulta Posto Web - Exportar revendedores em operação. Disponível em: <http://www.anp.gov. br> Acesso em: 25 maio 13.

20 Instituto Pereira Passos. (2010). População Residente de acordo com Áreas de Planejamento e Regiões Administrativas - Município do Rio de Janeiro. Disponível: <http://www.armazemdedados.rio.rj.gov.br/ arquivos/2961 pop\%20res doc\%20part\%20ocup m\%C3\%A9dia\%20 moradores_2010.XLS> Acesso em: 24 maio 13

21 Marconi, M. A., Lakatos, E. M. (2005). Metodologia do trabalho científico. Capítulo 9. Seção 9.2. $5^{\mathrm{a}}$ ed. São Paulo: Atlas. 